\title{
Modification of enteral diets in inflammatory bowel disease
}

\author{
Marian C. Aldhous*, Doris Meister and Subrata Ghosh \\ Gastro-intestinal Laboratory, Western General Hospital, Edinburgh EH4 2XU, UK
}

\begin{abstract}
The provision of food is thought to promote the maintenance of gut integrity. Nutrients are able to elicit and affect both systemic and mucosal immune responses. Enteral diet therapy has long been known to be efficacious in inflammatory bowel disease (IBD), particularly in childhood Crohn's disease. However, the mechanisms of action of these diets are not clear. Nutritional repletion, direct effects on the gut mucosa or decreased intestinal permeability have all been postulated as being important in nutritional therapy. There is some evidence that the enteral diet has a direct effect on the gut mucosa by reducing cytokine production and the accompanying inflammation, thus leading to decreased intestinal permeability. Modifications of enteral diet composition have been evaluated in many studies. Such modifications include fat and/or protein content and the addition of bioactive peptides. The fatty acid composition of the enteral diet seems to have a much greater impact on its efficacy than modification of the $\mathrm{N}$ source. As specific fatty acids are precursors of inflammatory mediators derived from arachidonic acid, the reduction in these components may be beneficial in nutritional therapy for IBD. Addition of bioactive peptides to enteral diet formulas may also have a role; such peptides may have specific growth factor or antiinflammatory actions. There is still much work to be done to define disease-specific enteral diet formulas that are effective as therapies for both Crohn's disease and ulcerative colitis.
\end{abstract}

Enteral diet formulas: Crohn's disease: Nutritional therapy: Inflammation

There is plenty of evidence to suggest that food and nutritional factors affect immune responses in the gut. Nutritional status, both at the macro- and micronutrient level, affects both systemic and mucosal immunity. Early work in our laboratory, under the auspices of the late Professor Anne Ferguson, showed that in protein-deprived mice there was a profound reduction in the induction of oral tolerance (Lamont et al. 1987a,b, 1988). It follows, therefore, that immunological functions of the gut and nutrient intake would be particularly important in gut disease (Ferguson, 1994). A breakdown of oral tolerance to gut bacteria has been hypothesised as a mechanism by which patients develop inflammatory bowel disease (IBD). Thus, if such immune responses are profoundly affected by nutrition, then nutritional therapy may have a role in the treatment of IBD.

IBD can be divided into two disease patterns, Crohn's disease (CD) and ulcerative colitis (UC), with distinct clinical, histological and immunological features. Both disease patterns show dysregulated cytokine balance; CD tends to be shifted towards a T-helper 1 (pro-inflammatory) phenotype and UC towards a T-helper 2 (anti-inflammatory) phenotype. This distinction in cytokine phenotype between the two disease states is not totally consistent with a Thelper 1-T-helper 2 split. Both diseases show an increase in inflammation of the gut mucosa, together with increased production of the pro-inflammatory cytokine interleukin (IL) $-1 \beta$ and a decrease in the anti-inflammatory cytokine IL-1 receptor antagonist (IL-1ra). Indeed, in both CD and UC a decrease in IL-1ra:IL-1 $\beta$ production has been described in isolated colonic biopsies compared with those from normal controls or patients with infectious colitis (Dionne et al. 1998). This imbalance has been proposed as being of pathogenic importance in IBD (Casini-Raggi et al. 1995).

The intestine is a metabolically active organ which maintains gut function through various mechanisms, e.g. peristalsis, secretory immunoglobulin A, mucin secretion. Starvation, and possibly parenteral feeding, predisposes the gut to metabolic and immunological deterioration of barrier function, leading to the release of pro-inflammatory cytokines and decreased gut permeability, allowing other macromolecules to cross. Gut contents stimulate immunological mechanisms such as intestinal immunoglobulin A 
production, which blocks the binding of bacteria to epithelial cells. Enteral feeding, as opposed to parenteral feeding, appears to maintain these mechanisms by providing food (Donnell et al. 1998; Minard \& Kudsk, 1998; Rowlands \& Gardiner, 1998).

\section{Enteral diets in inflammatory bowel disease}

There is little doubt that an enteral diet (ED) is effective in $\mathrm{CD}$, particularly in children, although there is some question as to the clinical efficacy of ED in UC. ED are important in re-establishing nutritional repletion in malnourished patients. There is also some evidence that ED have some effect on the disease activity itself, comparable with steroid therapy, although this factor has been debated widely. A meta-analysis (Griffiths et al. 1995) of trials comparing ED with steroids showed that although ED was effective in CD, it was still less effective than steroid treatment. However, other studies have shown that ED are equally as effective (Zoli et al. 1997). Either way, it is known that ED is a possible alternative in those patients who may have contraindications for steroid therapy in CD.

\section{Mechanism of action}

What really is not clear is the mechanism by which these diets have their action. There is still much discussion as to the best approach for trying to investigate such mechanisms. Although in vivo studies are the most relevant, as regards clinical efficacy and side effects, the actual mechanisms by which ED have their effect are hard to deduce, mainly because the gut is a difficult organ to study directly. Such studies may require repeated invasive or unpleasant procedures for patients in order to define a 'before and after' treatment effect, and subtle or transient changes may not be detected. Thus, knowing the best way to modify ED in order to increase clinical efficacy and reduce side effects becomes more difficult. In vitro studies are simpler to perform but, by their very nature of being in vitro, do not reproduce the many factors that affect gut function, and can only investigate defined and measurable effects such as cytokine production or changes in expression of particular molecules. However, in vitro studies of ED, looking at such specific mechanisms of action, may be useful in defining macro- and micronutrient effects on gut tissue, which can then be assessed further by in vivo studies.

Various hypotheses as to the action of ED in IBD have been proposed. There is still some discussion as to whether ED has a direct effect on the gut, or whether the efficacy of $\mathrm{ED}$ is due to indirect effects such as improvement in nutritional status. In one study of ED in $\mathrm{CD}$, both nourished and malnourished patients responded equally (Gorard et al. 1993). Other researchers have found that clinical improvement in disease activity occurred before changes in nutritional status were detected (Teahon et al. 1995; Croft et al. 2001), suggesting that ED has a direct effect on the gut.

Decreased intestinal permeability has also been proposed as a mechanism through which ED therapy may act. Clinical improvement of $\mathrm{CD}$ has been accompanied by decreases in urinary ${ }^{51}$ CrEDTA excretion and faecal excretion of
${ }^{111}$ In-labelled leucocytes (Teahon et al. 1991), or a decrease in quantitative leucocyte scintigraphy (Mansfield et al. 1995). Zoli et al. (1997), in a study comparing ED with steroids, showed a significant decrease in intestinal permeability with ED $(P<0 \cdot 05)$, but not with steroids, even though both treatment groups went into clinical remission. Studies from our own laboratory have also indicated a decrease in intestinal permeability in CD patients, through decreased protein (immunoglobulin G) loss in whole-gut lavage fluid (Ferguson et al. 1998), after treatment with an elemental ED for 2 weeks. This decrease in intestinal permeability was accompanied by a concomitant decrease in IL-1 $\beta$ levels. These results provide further evidence that ED have a direct effect on the gut, by changing cytokine levels, thus resulting in decreased inflammation, which in turn leads to decreased permeability.

\section{Elemental or polymeric enteral diets?}

More recent studies in our laboratory have begun to investigate the possible direct anti-inflammatory effect of ED, in an in vitro organ culture model, by monitoring changes in cytokine production (Shand et al. 2000). Ileal or colonic biopsies from patients with CD and UC were incubated with ED or medium alone for $24 \mathrm{~h}$. Supernatant fractions were collected and cytokines (IL-ra, IL-1 $\beta$ and IL-10) were measured by ELISA. Initial studies used an elemental formula ED (E028; Scientific Hospital Supplies, Liverpool, $\mathrm{UK}$ ), in which the $\mathrm{N}$ source was free amino acids, as opposed to polymeric ED, in which the $\mathrm{N}$ source was whole proteins or oligopeptides. We established that the biopsies maintained viability in culture, and we looked for changes in IL-1ra:IL-1 $\beta$; an increase in the ratio would indicate a decrease in IL- $1 \beta$ or an increase in IL-1ra production, i.e. an anti-inflammatory effect of ED in these experiments. Results showed that an increase in IL-1ra:IL-1 $\beta$ was obtained in biopsies from CD patients incubated with ED, but no changes in cytokine production were seen in biopsies from UC patients. Further studies used ED with oligopeptides (whey) or whole protein (casein) as the $\mathrm{N}$ source and found that the increased IL-1ra:IL-1 $\beta$ was not abolished. Indeed, if anything, for casein the effect was more pronounced. These results agree with those from clinical studies of elemental, oligopeptide or polymeric ED, which showed that there appears to be little difference between diet efficacy and the N source (Griffiths et al. 1995; Mansfield et al. 1995; Verma et al. 2000).

It has been proposed that elemental ED are effective as they provide gut rest or a low antigen load, through decreased protein content. However, the efficacy of polymeric ED and maintenance of remission through the supplementation of a normal diet with ED (Wilschanski et al. 1996) bring these theories into dispute. Indeed, in animal models too much 'gut rest', through use of parenteral nutrition or long-term treatment with an elemental ED, increases the likelihood of bacterial translocation or gut atrophy (Evers et al. 1990; Serizawa et al. 1994; Xu et al. 1998). Many polymeric ED are based on milk proteins and there is some evidence that casein and whey themselves have direct immune modulatory functions (Wong et al. 1996; Cross \& Gill, 1999). 


\section{Modification of fat composition of enteral diets}

ED, particularly those of an elemental formula, often have a low fat content, which is another possible mechanism of efficacy. However, studies comparing high- and low-fat ED have found no differences in achieving clinical remission of CD (Royall et al. 1994; Leiper et al. 2001). Although there may be little effect by changing the amount of fat in ED, there may be some benefit from modification of the fat composition. We have carried out experiments in which colonic tissues from IBD patients were incubated with ED containing specific oils. Preliminary results indicated that incubation of tissue from UC patients with ED containing fish oil led to a significant increase in IL-ra:IL-1 $\beta$ $(P<0.05)$. However, for tissue derived from CD patients, incubation with ED containing fish oil had little effect on cytokine production profiles (Meister et al. 2001b).

There has been much interest in dietary supplementation with different fats in inflammatory conditions (de Pablo \& de Cienfuegos, 2000; James et al. 2000). Previous studies of the use of $n-3$ dietary fats in IBD have given conflicting results (for review, see Beluzzi et al. 2000). In UC several studies have indicated that supplementation of ED with fish oil may be beneficial, particularly as concomitant decreases were seen in markers of inflammation (e.g. leukotriene $B_{4}$ levels) in rectal mucosa. However, not all studies showed significant clinical differences, possibly due to small numbers (Lorenz et al. 1989; Aslan \& Triadafilopoulos, 1992; Hawthorne et al. 1992; Stenson et al. 1992). In animal models of UC administration of $n-3$ fatty acids by oral and topical enema routes indicated that reduced pathology and decreases in leukotriene levels could be achieved (Yuceyar et al. 1999). Moreover, there may also be a decrease in the colonic antioxidant defence systems, which may promote oxidative injury at the site of inflammation (Nieto et al. 1998), and thus explain the clinical results which showed decreases in pathology or inflammation but less effect on clinical remission rates. Although some in vivo studies have indicated little effect of fish oil in CD (Lorenz et al. 1989; Lorenz-Meyer et al. 1996), other studies have indicated that fish oil may be beneficial in CD (Beluzzi et al. 1996). The discrepancy between our in vitro results for fish oil-supplemented ED on CD and UC may be due to the fact that, as already mentioned, in vitro studies use a reductionist model, which may not parallel effects that occur in vivo. Our studies have only monitored one mechanism, i.e. alterations in cytokine production, albeit an important pathogenic mechanism in IBD (Casini-Raggi et al. 1995). It has been shown that fish oil reduced production of inflammatory cytokines from mononuclear cells (Endres et al. 1989). However, other inflammatory mechanisms which are altered by dietary fat intake and composition may be differentially important in CD and UC. For example, macrophage cytotoxic function has been shown to be affected by dietary fat composition (Wallace et al. 2000), as has the antigenpresenting function of monocytes (Hughes \& Pinder, 2000), the production of inflammatory mediators (for review, see James et al. 2000) and cellular immune functions (for review, see Calder, 1998).

We have also cultured colonic tissues from IBD patients with ED containing sunflower oil, which gave significant increases in IL-1ra:IL-1 $\beta$ in both $\mathrm{CD}$ and UC tissues $(P<0.05$ in both cases $)$ but was not seen when tissues were incubated with ED containing safflower oil (Meister et al. $2001 a$ ). These results indicate that substitution by other fats in ED may be important for CD and UC therapy. Although in these ED preparations safflower oil-substituted ED contains more polyunsaturated fatty acids in total, the main difference in the fatty acid composition is that the sunflower oil-substituted ED used here contained no linoleic acid. Linoleic acid is a precursor of arachidonic acid, which in turn is a precursor of the inflammatory eicosanoid mediators leukotriene $B_{2}$, prostaglandin $E_{2}$ and thromboxane $A_{2}$, all of which have been implicated in IBD pathogenesis. Mucosal phospholipids derived from polyunsaturated fatty acids have been shown to be increased in the plasma membranes of active $\mathrm{CD}$, possibly contributing to eicosanoid synthesis and inflammation (Pereira et al. 1996). Studies from Japan have implicated that dietary intake of $n-6$ polyunsaturated fatty acids, compared with $n-3$ polyunsaturated fatty acids, was a risk factor for development of CD (Shoda et al. 1996). However, a case-control study of CD patients, both newly diagnosed and with longstanding disease, indicated that intake of fat (both quality and quantity) was not different between patients and controls, but that fat metabolism in CD patients was changed, so that different fatty acids were present in plasma membrane phospholipids of $\mathrm{CD}$ patients compared with controls (Geerling et al. 1999). In addition, increased lipid oxidation has also been reported in CD (Mingrone et al. 1996), indicating that increased lipid intake may be beneficial in CD.

\section{Bioactive peptides}

Most studies of ED in IBD have concentrated on the macronutrients, i.e. protein and fat content or composition. It is possible that bioactive peptides may be important, and should perhaps be included in ED formulas. There are growth factors and peptides that could be very important in the maintenance of gut integrity in inflammatory diseases, many of which are present in colostrum (Playford et al. 2000). One such peptide is epidermal growth factor, which stimulates intestinal epithelial cell growth. A recent study in which patients with UC were treated with enemas containing epidermal growth factor indicated the efficacy of such growth factors in IBD (Sinha et al. 2001). Another bioactive peptide is transforming growth factor- $\beta$, which also occurs in colostrum and is known to have an antiinflammatory effect on intestinal cell lines (Donnet-Hughes et al. 2000). Its potential benefit has been borne out in a study by Fell et al. (2000) who used a commercially available casein-based diet, which also contained transforming growth factor- $\beta_{2}$ in the treatment of paediatric CD and found a decrease in pro-inflammatory cytokine mRNA in the gut mucosa.

\section{Conclusion}

In summary, many studies have shown that ED is an effective therapy in patients with CD. Modification of ED with different fatty acids, bioactive peptides and, to a lesser extent, $\mathrm{N}$ source may have a direct effect on the 
inflammatory mediators produced in both $\mathrm{CD}$ and $\mathrm{UC}$, thus increasing the efficacy of ED in both forms of IBD. Further studies are required to ascertain how ED formulas should be modified in ways that are disease-specific for CD and UC.

\section{Acknowledgements}

We acknowledge Sandra Giffen and Wendy Johnston of Scientific Hospital Supplies, Liverpool, UK for their donation of the enteral diet formulas used in our experiments. D. M. is funded by Scientific Hospital Supplies research grant to Intestinal Immunology Research Fund.

\section{References}

Aslan A \& Triadafilopoulos G (1992) Fish oil fatty acid supplementation in ulcerative colitis: a double-blind, placebo-controlled, crossover study. American Journal of Gastroenterology 87, 432-437.

Beluzzi A, Boschi S, Brignola C, Munarini A, Cariani G \& Miglio F (2000) Polyunsaturated fatty acids and inflammatory bowel disease. American Journal of Clinical Nutrition 71, Suppl. 1, 339S-342S.

Beluzzi A, Brignola C, Campieri M, Pera A, Boschi S \& Miglioli M (1996) Effect of an enteric-coated fish-oil preparation on relapses in Crohn's disease. New England Journal of Medicine 334, 1557-1560.

Calder PC (1998) Dietary fatty acids and the immune system. Nutrition Reviews 56, S70-S83.

Casini-Raggi V, Kam L, Chong YJT, Fiocchi C, Pizarro TT \& Cominelli F (1995) Mucosal imbalance of IL-1 and IL-1 receptor antagonist in inflammatory bowel disease. A novel mechanism of chronic intestinal inflammation. Journal of Immunology 154, 2434-2440.

Croft NM, Kelly EJ, Bannerjee K, Dryhurst K \& Sanderson I (2001) Diets can modulate the inflammatory response in vivo and in vitro. Gut $\mathbf{4 8}$, Suppl. 1, A2.

Cross ML \& Gill HS (1999) Modulation of immune function by a modified bovine whey protein concentrate. Immnunology and Cell Biology 77, 345-350.

de Pablo M \& de Cienfuegos GA (2000) Modulatory effects of dietary lipids on immune system functions. Immunology and Cell Biology 78, 31-39.

Dionne S, D'Agata ID, Hiscott J, Vanounou T \& Seidman EG (1998) Colonic explant production of IL-1 and its receptor antagonist is imbalanced in inflammatory bowel disease. Clinical and Experimental Immunology 112, 435-442.

Donnell SC, Taylor N, van Saene HKF, Pierro A \& Lloyd DA (1998) Nutritional implications of gut overgrowth and selective decontamination of the digestive tract. Proceedings of the Nutrition Society 57, 381-387.

Donnet-Hughes A, Duc N, Serrant P, Vidal K \& Schiffrin EJ (2000) Bioactive molecules in milk and their role in health and disease: the role of transforming growth factor- $\beta$. Immunology and Cell Biology 78, 74-79.

Endres S, Ghorbani R, Kelley VE, Georgilis K, Lonnemann G, van der Meer JWM, Cannon JG, Rogers TS, Klempner MS, Weber PC, Schaefer EJ, Wolff SM \& Dinarello CA (1989) The effect of dietary supplementation with $n-3$ polyunsaturated fatty acids on the synthesis of interleukin-1 and tumor necrosis factor by mononuclear cells. New England Journal of Medicine 320, 265-271.

Evers BM, Izukuru M, Townsend CM Jr, Uchida T \& Thompson JC (1990) Differential effects of gut hormones on pancreas and intestinal growth during administration of an elemental diet. Annals of Surgery 211, 630-638.
Fell JME, Paintin M, Arnaud-Battandier F, Beattie RM, Hollis A, Kitching P, Donnet-Hughes A, MacDonald TT \& Walker-Smith JA (2000) Mucosal healing and a fall in mucosal proinflammatory cytokine mRNA induced by a specific oral polymeric diet in paediatric Crohn's disease. Alimentary Pharmacology and Therapeutics 14, 281-289.

Ferguson A (1994) Immunological functions of the gut in relation to nutritional state and mode of delivery of nutrients. Gut $\mathbf{3 5}$, Suppl. 1, S10-S12.

Ferguson A, Glen M \& Ghosh S (1998) Crohn's disease: nutrition and nutritional therapy. Ballière's Clinical Gastroenterology 12, 93-114.

Geerling BJ, van Houwelingen AC, Badart-Smook A, Stockbrügger RW \& Brummer R-JM (1999) Fat intake and fatty acid profile in plasma phospholipids and adipose tissue in patients with Crohn's disease compared with controls. American Journal of Gastroenterology 94, 410-417.

Gorard DA, Hunt JB, Payne-James JJ, Palmer KR, Rees RGP, Clark ML, Farthing MJG, Misiewicz JJ \& Silk DBA (1993) Initial response and subsequent course of Crohn's disease treated with elemental diet or prednisolone. Gut 34, 1198-1202.

Griffiths AM, Ohlsson A, Sherman PM \& Sutherland LR (1995) Meta-analysis of enteral nutrition as a primary treatment of active Crohn's Disease. Gastroenterology 108, 1056-1067.

Hawthorne AB, Daneshmend TK, Hawkey CJ, Belluzi A, Everitt SJ, Holmes GKT, Malkinson C, Shahhen MZ \& Willars JE (1992) Treatment of ulcerative colitis with fish oil supplementation: a prospective 12 month randomised controlled trial. Gut 33, 922-928.

Hughes DA \& Pinder AC (2000) n-3 polyunsaturated fatty acids inhibit the antigen-presenting function of human monocytes. American Journal of Clinical Nutrition 71, Suppl. 1, 357S-360S.

James MJ, Gibson RA \& Cleland LG (2000) Dietary polyunsaturated fatty acids and inflammatory mediator production. American Journal of Clinical Nutrition 71, Suppl. 1, 343S-348S.

Lamont AG, Gordon M \& Ferguson A (1987a) Oral tolerance in protein-deprived mice. I. Profound antibody tolerance but impaired DTH tolerance after antigen feeding. Immunology $\mathbf{6 1}$, 333-337.

Lamont AG, Gordon M \& Ferguson A (1987b) Oral tolerance in protein-deprived mice. II. Evidence of normal 'gut processing' of ovalbumin, but suppressor cell deficiency in deprived mice. Immunology 61, 339-343.

Lamont AG, Gordon M \& Ferguson A (1988) T lymphocyte function in protein deprived mice. Clinical and Experimental Immunology 72, 113-117.

Leiper K, Woolner J, Mullan MMC, Parker T, van der Vleit M, Fear S, Rhodes JM \& Hunter JO (2001) A randomised controlled trial of high versus low long chain triglyceride whole protein feed in active Crohn's disease. Gut 48, Suppl. 1, A2.

Lorenz R, Weber PC, Szimnau P, Heldwien W, Strasser T \& Loeschke K (1989) Supplementation with $n$-3 fatty acids from fish oil in chronic inflammatory bowel disease - a randomised, placebo-controlled, double-blind, cross-over trial. Journal of Internal Medicine 225, Suppl. 1, 225-232.

Lorenz-Meyer H, Bauer P, Nicolay C, Schulz B, Purrmann J, Fleig WE, Scheuren C, Koop I, Pudel V, Carr L \& German Crohn's Disease Study Group (1996) Omega-3 fatty acids and low carbohydrate diet for maintenance of remission in Crohn's disease. Scandinavian Journal of Gastroenterology 31, 778-785.

Mansfield JC, Giaffer MH \& Holdsworth CD (1995) Controlled trial of oligopeptide versus amino acid diet in treatment of active Crohn's disease. Gut 36, 60-66. 
Meister D, Aldhous MC, Bode J, Shand A, Johnson W, Giffen S \& Ghosh S (2001a) Anti-inflammatory effect of elemental diet in vitro depends on fatty acid composition. Gut 48, Suppl. 1, A2.

Meister D, Aldhous MC, Bode J, Shand A, Johnson W, Giffen S \& Ghosh S(2001b) Fish oil substituted elemental diet in ulcerative colitis. Gut 48, Suppl. 1, A73.

Minard G \& Kudsk KA (1998) Nutritional support and infection: does the route matter? World Journal of Surgery 22, 213-219.

Mingrone G, Greco AV, Benedetti G, Capristo E, Semeraro R, Zoli G \& Gasbarrini G (1996) Increased lipid oxidation in Crohn's disease. Digestive Disease and Sciences 41, 72-76.

Nieto N, Fernandez MI, Torres MI, Ríos A, Suarez MD \& Gil A (1998) Dietary monounsaturated $n-3$ and $n-6$ long-chain polyunsaturated fatty acids affect cellular antioxidant defence system in rats with experimental ulcerative colitis induced by trinitrobenzene sulphonic acid. Digestive Disease and Sciences 43, 2676-2687.

Pereira SP, Cassel TB, Engelman JL, Sladen GE, Murphy GM \& Dowling RH (1996) Plasma arachidonic acid-rich phospholipids in Crohn's disease: response to treatment. Clinical Science 91, 509-512.

Playford RJ, Macdonald CE \& Johnson WS (2000) Colostrum and milk-derived peptide growth factors for the treatment of gastrointestinal disorders. American Journal of Clinical Nutrition 72, 5-14.

Rowlands BJ \& Gardiner KR (1998) Nutritional modulation of gut inflammation. Proceedings of the Nutrition Society 57, 395-401.

Royall D, Jeejeebhoy KN, Baker JP, Allard JP, Habal FM, Cunnane SC \& Greenberg GR (1994) Comparison of amino acid v peptide based enteral diets in active Crohn's disease: clinical and nutritional outcome. Gut 35, 783-787.

Serizawa H, Miura S, Tashiro H, Imaeda H, Shiozaki H, Ohkubo N, Kimura H, Tanaka S \& Tsuchiya M (1994) Alteration of mucosal immunity after long-term ingestion of an elemental diet in rats. Journal of Parenteral and Enteral Nutrition 18, 141-147.

Shand AG, Meister D, Aldhous M, Anderson N \& Ghosh S (2000) Direct anti-inflammatory effect of elemental diet on Crohn's tissue in vitro. Gut 46, Suppl. 11, W42.

Shoda R, Matsueda K, Yamato S \& Umeda N (1996) Epidemiologic analysis of Crohn disease in Japan: increased dietary intake of $n-6$ polyunsaturated fatty acids and animal protein relates to the increased incidence of Crohn disease in Japan. American Journal of Clinical Nutrition 63, 741-745.

Sinha A, Nightingale JMD, West KP, Berlanga-Acosta J \& Playford RJ (2001) Can left-sided ulcerative colitis be treated with epidermal growth factor enemas? Gut 48, Suppl. 1, A1.

Stenson WF, Cort D, Rodgers J, Burakoff R, DeSchryverKeeskemeti K, Gramlich TL \& Beeken W (1992) Dietary supplementation with fish oil in ulcerative colitis. Annals of Internal Medicine 116, 609-614.

Teahon K, Pearson M, Smith T \& Bjarnason I (1995) Alterations in nutritional status and disease activity during treatment of Crohn's disease with elemental diet. Scandinavian Journal of Gastroenterology 30, 54-60.

Teahon K, Smethurst P, Pearson M, Levi AJ \& Bjarnason I (1991) The effect of elemental diet on intestinal permeability and inflammation in Crohn's disease. Gastroenterology 101, 84-89.

Verma S, Brown S, Kirkwood B \& Giaffer MH (2000) Polymeric versus elemental diet as primary treatment in active Crohn's disease: a randomised double-blind trial. American Journal of Gastroenterology 95, 735-739.

Wallace FA, Neely SJ, Miles EA \& Calder PC (2000) Dietary fats affect macrophage-mediated cytotoxicity towards tumour cells. Immunology and Cell Biology 78, 40-48.

Wilschanski M, Sherman P, Pencharz P, Davis L, Corey M \& Griffiths A (1996) Supplementary enteral nutrition maintains remission in paediatric Crohn's disease. Gut 38, 543-548.

Wong CW, Seow HF, Liu AH, Husband AJ, Smithers GW \& Watson DL (1996) Modulation of immune responses by bovine beta-casein. Immunology and Cell Biology 74, 323-329.

Xu D, Lu Q \& Deitch EA (1998) Elemental diet-induced bacterial translocation associated with systemic and intestinal immune suppression. Journal of Parenteral and Enteral Nutrition 22, $37-41$.

Yuceyar H, Ozutemiz O, Huseyinov A, Saruc M, Alkanat M, Bor S, Coker I \& Batur Y (1999) Is administration of $n$-3 fatty acids by mucosal enema protective against trinitrobenzene-induced colitis in rats? Prostaglandins, Leukotrienes and Essential Fatty Acids 61, 339-345.

Zoli G, Carè M, Parazza M, Spanò C, Biagi PL, Bernardi M \& Gasbarrini G (1997) A randomised controlled study comparing elemental diet and steroid treatment in Crohn's disease. Alimentary Pharmacology and Therapeutics 11, 735-740. 